\title{
Transcatheter Aortic Valve Implantation
}

National Cancer Institute

\section{Source}

National Cancer Institute. Transcatheter Aortic Valve Implantation. NCI Thesaurus. Code C100022.

Use of a thin tube to deliver an artificial valve apparatus between the left ventricle of the heart and the aorta. (ACC) 